\title{
Use of Magnetic Forces in Orthodontics: A Review
}

\author{
Aakash Shah*, Purvesh Shah, Santosh Kumar Goje, Romil Shah, Bhumi Modi \\ Department of Orthodontics and Dentofacial Orthopedics, K.M. Shah Dental College and Hospital, \\ Vadodara, Guiarat, India
}

dai: https://doi.org/10.21467/ajgr.1.1.30-34

* Corresponding Author email:

aakashshah108@gmail.com

Article History

Received: 12 February 2017

Accepted: 19 February 2017

Published: 19 February 2017

Student(s)

- $\quad$ Aakash Shah

Academic Year: 2016-17

Course Level: Master Degree

Course Name: Master of Dental Surgery (M.D.S.)

Course year: $3^{\text {rd }}$ year

$\operatorname{Mentor}(s)$

- Purvesh Shah

- Santosh Kumar Goje

- Romil Shah

- Bhumi Modi

\begin{abstract}
The application of magnetic forces to clear aligner therapy would create a magnetic force interaction that can theoretically make the movement of teeth in any direction possible and easier. With this objective in mind the following section of this literature review deals with the use of clear thermoplastics in orthodontics. The current literature regarding the efficacy of the appliance is examined to highlight the need for enhancement of this system.
\end{abstract}

Keywords: Orthodontics, Magnetic Forces.

\section{Introduction}

Magnets were earlier utilized in dentistry for improving the retention of maxillofacial prosthesis [1]-[3] and dentures [4], [5]. Magnetic forces are utilized in orthodontics for orthopaedic correction [6]-[11] and tooth movement [12]-[16]. The use of magnets for generating orthodontic forces has been a subject of increasing interest. This article will review the application of magnets in the field of orthodontics. In orthodontics, the conventional force delivery systems utilize wires, elastics and extra-oral devices [17], [18]. The possibility of using magnetic forces in orthodontics has been advocated as there are numerous benefits. Darendeliler et al. [19] commented that although rare earth magnets offer advantages over traditional fixed appliances with regard to continuous force delivery, these positives have not been significant enough to lead to widespread clinical application. Several animal and clinical studies have documented the reliability of using magnetic forces for different tooth movements. The following section will summaries the reported application of magnet forces for tooth movement. 
Shah et al., Adv.J. Grad. Res.; Vol. 1 Issue 1, pp: 30-34, January 2017

\section{Molar Distalisation}

Bondemark and Kurol examined the force output from prefabricated repelling SmCo5 magnets $(4 \times 5 \times 2 \mathrm{~mm})$ in an experimental model and found that the forces were suitable for distalisation. A pole face distance of $0.5 \mathrm{~mm}$ was reported to correspond with the recommended force for moving permanent molars distally 180 grams. If the molar moved $1 \mathrm{~mm}$ the force lowered to $100 \mathrm{grams}$. Based on these findings the authors recommended activation of the force system be performed at 4-5 week intervals and recommended the pole distance be carefully checked at each appointment [17]-[20]. However, there is no consensus regarding the activation in the literature with some authors recommending weekly activation, [14] while others activate the magnets every 3 to 5 weeks. Bondemark et al. [20], [21] contrasted the usefulness of superelastic nickel titanium coils versus repelling magnets in maxillary first and second molar distalisation over a 6-month period [16]. Eighteen patients were treated with the two systems, one on each side, and were matched to deliver 225 grams of force on activation. The magnets and springs were activated every 4 weeks, which may have been to the disadvantage of the magnet side as the force intensity on this side had a faster decrease. Mean distal molar movement was greater for the coils, $3.2 \mathrm{~mm}$ compared to $2.2 \mathrm{~mm}$ for the magnets [22]. Frequent complaints of discomfort were on the magnet side [16]. A similar study was conducted by Erverdi but with weekly activation of the magnets and nickel-titanium coils were still found to be more effective [22]. Bondemark conducted a retrospective comparison of two groups of 21 adolescents treated with repelling magnets or a new lingual Ni-Ti coil appliance. The results indicated that the new Ni-Ti appliance was a better choice due to the design preventing molar tipping (2.2 degrees vs. 8.8 degrees) and its single activation [23].

Bondemark and Kurol later evaluated radiographically the impact of these treatment techniques on proximal alveolar bone level changes. The treated cases had a statistically significant but small decrease in alveolar bone level $(0.2 \mathrm{~mm}$ versus $0.1 \mathrm{~mm}$ for the control). There was no statistically significant difference between teeth moved rapidly by magnets or superelastic coils. Thus, with respect to the influence on bone level, the authors concluded that there was no difference between an interrupted continuous force system produced by a magnet and a more continuous force produced by the superelastic nickel-titanium coils [24].

\section{Extrusion}

To achieve rapid extrusion forces of 50 to $60 \mathrm{cN}$ are recommended, approximately twice as much as that required for normal extrusion of a single rooted tooth. The magnetic system consisted of either one or two cylindrical $\mathrm{NdFeB}$ magnets $(3 \mathrm{~mm} \times 2 \mathrm{~mm}$ ) placed in each tooth and a larger magnet $(5 \times 5 \times 2 \mathrm{~mm})$ in the appliance. The force-distance curve for the magnets demonstrated that the gap between the magnets should not exceed $2 \mathrm{~mm}$ to ensure a minimum force of $50 \mathrm{cN}$ was applied. The roots were successfully extruded 2 to $3 \mathrm{~mm}$ with a force range from 50 to $240 \mathrm{cN}$ during a treatment period of 9 to 11 weeks.

\section{Magnets and Impacted Teeth}

With the eruption of teeth, the magnet seized in the appliance can be shifted to direct the eruption of the tooth and minimize the risks to adjacent teeth [25], [26]. This technique exploits the unique characteristic of a magnetic field to prevail between any organic medium [12]. There does not need to be direct contact between the magnets as they can exert force through bone and mucosa [25], [26]. As the eruptive process is through normal, closed mucoperiosteum it has been stated that this ensures that a healthy periodontal ligament will encircle the tooth [27]. The application of magnetic forces has been used increasingly and has been applied to the eruption of incisors, premolars and molars [12]. The application of this approach for the eruption of impacted premolars was described by Sandler 1991. Small neodymium-iron-boron magnets $(3 \times 3 \times 1 \mathrm{~mm})$ were bonded to the teeth that were impacted while a second larger magnet $(5 \times 5 \times 2$ or $3 \mathrm{~mm})$ was integrated into a removable appliance. No reference was made to the force levels generated by this configuration of magnets. 
Yuksel et al. also described the treatment of impacted premolars in several members of the same family with this technique. Cole et al. [28] described the application of magnetic traction to two premolars and six molars in 8 paediatric patients. The failure of one premolar to erupt was attributed to its unfavourable position. In the seven successful cases the distance between the magnets did not exceed $8 \mathrm{~mm}$, suggesting that distances up to this magnitude can provide sufficient force to induce tooth movement.

Recently, $\mathrm{Li}$ et al presented a case in which orthodontic traction of an upper left canine was achieved using a magnet [29] in a 15-year-old female. A metal bracket was bonded to the impacted tooth following surgical exposure and was under magnetic force, with direction controllable by adjustment of a wire extension arm from a removable appliance. After 12 months two-thirds of the crown had erupted and the patient was ready to receive simple fixed appliance therapy. The authors suggested that magnetic traction with a removable appliance was safe, effective and comfortable [29]. Physical properties of permanent magnets have to be taken into consideration when designing eruptive magnetic devices [12]. Mancini et al investigated the attractive forces generated by five different sized $\mathrm{NdFeB}$ magnets in a total of nine combinations for tooth extrusion [27]. Vardimon et al performed a three-dimensional analysis of the magnetic force systems of the same magnetic bracket attracted by diverse designs of intraoral magnets using the orthodontic measurement and simulation system (OMSS) [30]. It was concluded that a magnet with a large pole surface area exhibited the most efficient guidance and had a greater clinical range [12]. The authors also commented that the size of the magnet attached to the device could be increased to a certain extent to enhance performance, in contrast to the magnet attached to the tooth.

\section{Application of Magnetic Forces for Tooth Movement in Combination with Clear Thermoplastic Appliances}

Clear sequential aligner therapy has become a popular alternative to fixed appliances in recent years with the increased demand for aesthetic treatment options. Clear aligner therapy or clear sequential aligner treatment refers to a sequence of clear thermoplastic appliances made on a series of casts with reset teeth, each incorporating another small amount of tooth movement [18]. Despite their superior aesthetics this appliance is less effective than fixed appliance therapy [31]. To overcome some of the limitations of the appliance composite resin attachments are placed on the teeth. Attachments are generally placed on the teeth to increase the undercuts and retention of the appliance to facilitate the desired tooth movement [18]. However, the current attachments are considered to be only partially effective [32], [33]. An improved system utilizing small magnetic attachments has been put forward to enhance the capabilities of this appliance. In this system a sequential orthodontic appliance is combined with at least one magnetic attachment positioned in an attractive or repulsive configuration bonded to the surface of a tooth and a magnet encased in the body of the thermoplastic material. The magnets used in this system are neodymium iron boron $(\mathrm{NdFeB})$ rare earth magnets which have the highest energy per unit volume of any commercially existing magnetic material [25]. A laboratory based study was performed to observe the three-dimensional physical properties of small

neodymium iron boron magnets that could be utilized in this manner, to determine if force levels sufficient to induce tooth movement could be generated and to observe the effect of different magnet morphologies on the force-displacement characteristics.

\section{Conclusions}

Magnetic forces are now used most commonly in orthodontics. Various myofunctional appliances are used for growth modification in which magnets are embedded for better results. Future research should be done to formulate appliances of various designs by incorporating magnets for better treatment outcome and faster results. 
Shah et al., Adv.J. Grad. Res.; Vol. 1 Issue 1, pp: 30-34, January 2017

\section{How to cite this article:}

Shah, A., Shah, P., Goje, S., Shah, R., \& Modi, B. (2017). Use of Magnetic Forces in Orthodontics: A Review.Advanced Journal of Graduate Research, 1(1), 30-34. doi: https://doi.org/10.21467/ajgr.1.1.30-34

\section{References}

[1] N. Javid, "The use of magnets in a maxillofacial prosthesis," J. Prosthet. Dent., vol. 25, no. 3, pp. 334-341, Mar. 1971.

[2] J. E. Robinson, "Magnets for the retention of a sectional intraoral prosthesis," J. Prosthet. Dent., vol. 13, no. 6, pp. 1167-1171, Nov. 1963.

[3] J. Nadeau, "Maxillofacial prosthesis with magnetic stabilizers,” J. Prosthet. Dent., vol. 6, no. 1, pp. 114-119, Jan. 1956.

[4] H. Freedman, "Magnets to Stabilize Dentures," J. Am. Dent. Assoc., vol. 47, no. 3, pp. 288-297, Sep. 1953.

[5] S. Winkler and M. H. Pearson, "The effectiveness of embedded magnets in complete dentures during speech and mastication: a cineradiographic study.," Dent. Dig., vol. 73, no. 3, p. 118, Mar. 1967.

[6] A. D. Vardimon, T. M. Graber, L. R. Voss, and T. P. Mulfer, "Functional orthopedic magnetic appliance (FOMA) III-Modus operandi," Am. J. Orthod. Dentofac. Orthop., vol. 97, no. 2, pp. 135-148, Feb. 1990.

[7] M. A. Darendeliler and J.-P. Joho, "Magnetic activator device II (MAD II) for correction of Class II, division 1 malocclusions," Am. J. Orthod. Dentofac. Orthop., vol. 103, no. 3, pp. 223-239, Mar. 1993.

[8] A. D. Vardimon, J. J. Stutzmann, T. M. Graber, L. R. Voss, and A. G. Petrovic, "Functional orthopedic magnetic appliance (FOMA) II-Modus operandi," Am. J. Orthod. Dentofac. Orthop., vol. 95, no. 5, pp. 371-387, May 1989.

[9] A. D. Vardimon, T. M. Graber, L. R. Voss, and E. Verrusio, "Magnetic versus mechanical expansion with different force thresholds and points of force application," Am. J. Orthod. Dentofac. Orthop., vol. 92, no. 6, pp. 455-466, Dec. 1987.

[10] M. ALI DARENDELILER, M. CHIARINI, and J.P. JOHO, "Early Class III Treatment with Magnetic Appliances,” J. Clin. Orthod., vol. 27, no. 10, pp. 563-569, 1993.

[11] E. L. Dellinger, "A clinical assessment of the Active Vertical Corrector-A nonsurgical alternative for skeletal open bite treatment," Am. J. Orthod., vol. 89, no. 5, pp. 428-436, May 1986.

[12] A. D. Vardimon, T. M. Graber, D. Drescher, and C. Bourauel, "Rare earth magnets and impaction," Am. J. Orthod. Dentofac. Orthop., vol. 100, no. 6, pp. 494-512, Dec. 1991.

[13] A. M. Blechman, "Magnetic force systems in orthodontics," Am. J. Orthod., vol. 87, no. 3, pp. 201-210, Mar. 1985.

[14] A. A. Gianelly, A. S. Vaitaa, and W. M. Thomas, "The use of magnets to move molars distally," Am. J. Orthod. Dentofac. Orthop., vol. 96, no. 2, pp. 161-167, Aug. 1989.

[15] ANTHONY A. GIANELly, ALGIRDAS S. VAITAS, WILlIAM M. THOMAS, and DEBI G. BERGER, "Distalization of Molars with Repelling Magnets," J. Clin. Orthod., vol. 22, no. 1, pp. 40-44, 1988.

[16] Lars Bondemark, Jüri Kurol, and Mats Bernhold, "Repelling magnets versus superelastic nickel-titanium coils in simultaneous distal movement of maxillary first and second molars," Angle Orthod., vol. 64, no. 3, pp. 189-198, 1994.

[17] L. Bondemark and J. Kurol, "Force-distance relation and properties of repelling Sm-Co 5 magnets in orthodontic clinical use: an experimental model," Eur. J. Oral Sci., vol. 100, no. 4, pp. 228-231, Aug. 1992.

[18] W. R. Proffit, H. W. Fields, and D. M. Sarver, Contemporary orthodontics. Elsevier/Mosby, 2013.

[19] O. Ronning, "The use of magnets in orthodontic therapy: panel discussion," Eur. J. Orthod., vol. 15, no. 5, pp. 421-424, Oct. 1993.

[20] L. Bondemark and J. r. Kurol, "Distalization of maxillary first and second molars simultaneously with repelling magnets," Eur. J. Orthod., vol. 14, no. 4, pp. 264-272, Aug. 1992.

[21] A. M. Blechman Tappan, "Repelling magnets versus super elastic nickel-titanium coils," Angle Orthod., vol. 65, no. 1, pp. 8-9, 1995.

[22] N. Erverdi, O. Koyutürk, and N. Küçükkeles, "Nickel-titanium coil springs and repelling magnets: a comparison of two different intraoral molar distalization techniques.," Br. J. Orthod., vol. 24, no. 1, pp. 47-53, Feb. 1997.

[23] L. Bondemark, "A comparative analysis of distal maxillary molar movement produced by a new lingual intra-arch Ni-Ti coil appliance and a magnetic appliance," Eur. J. Orthod., vol. 22, no. 6, pp. 683-695, Dec. 2000.

[24] B. Lars and K. Jüri, "Proximal alveolar bone level after orthodontic treatment with magnets, superelastic coils and straight-wire appliances," Angle Orthod., vol. 67, no. 1, pp. 7-14, 1997.

[25] J. H. Noar and R. D. Evans, "Rare Earth Magnets in Orthodontics: An Overview," Br. J. Orthod., vol. 26, no. 1, pp. 29-37, Mar. 1999.

[26] M. A. Darendeliler, A. Darendeliler, and M. Mandurino, "Clinical application of magnets in orthodontics and biological implications: a review," Eur. J. Orthod., vol. 19, no. 4, pp. 431-442, Aug. 1997.

[27] G. Mancini, J. Noar, and R. Evans, "The physical characteristics of neodymium iron boron magnets for tooth extrusion," Eur. J. Orthod., vol. 21, no. 5, pp. 541-550, Oct. 1999.

[28] B. O. I. Cole, A. J. Shaw, R. S. Hobson, J. H. Nunn, R. R. Welbury, J. G. Meechan, and N. J. A. Jepson, "The role of magnets in the management of unerupted teeth in children and adolescents," Int. J. Paediatr. Dent., vol. 13, no. 3, pp. 204-207, Apr. 2003.

[29] L. C. F. Li, R. W. K. Wong, and N. M. King, "Orthodontic traction of impacted canine using magnet: a case report," Cases J., vol. 1, no. 1 , p. $382,2008$.

[30] D. Drescher, C. Bourauel, and M. Thier, "Application of the orthodontic measurement and simulation system (OMSS) in orthodontics," Eur. J. Orthod., vol. 13, no. 3, pp. 169-178, Jun. 1991.

[31] G. Djeu, C. Shelton, and A. Maganzini, "Outcome assessment of Invisalign and traditional orthodontic treatment compared with the American Board of Orthodontics objective grading system,” Am. J. Orthod. Dentofac. Orthop., vol. 128, no. 3, pp. 292-298, Sep. 2005. 
Use of Magnetic Forces in Orthodontics: A Review

[32] L. Joffe, “Invisalign ${ }^{\circledR}$ : early experiences," J. Orthod., vol. 30, no. 4, pp. 348-352, Dec. 2003.

[33] N. D. Kravitz, B. Kusnoto, B. Agran, and G. Viana, "Influence of Attachments and Interproximal Reduction on the Accuracy of Canine Rotation with Invisalign,” Angle Orthod., vol. 78, no. 4, pp. 682-687, Jul. 2008.

\section{Publish your research article in AIJR journals-}

$\checkmark$ Online Submission and Tracking

$\checkmark$ Peer Reviewed

$\checkmark$ Rapid decision

$\checkmark$ Immediate Publication after acceptance

$\checkmark$ Open Access (Articles freely available online)

$\checkmark$ Retain full copyright of your article.

Submit your article at journals.aijr.in 